\title{
OLHAR, OUVIR E ESCREVER NOS JÚRIS DE POLICIAIS MILITARES DE SÃO PAULO ${ }^{1} / /$ Poliana da Silva Ferreira ${ }^{2}$
}

\section{Palavras-chave}

Júri de policiais militares / homicídios dolosos praticados por policiais militares / julgamentos de $\mathrm{PM} /$ morte decorrente de intervenção policial

HIIIIIIIIIIIIIIIIIIIIIIIIIIIIIIIIII

\section{Sumário}

\section{Introdução}

2 Estratégias Metodológicas

2.1 O escrever sobre a observação dos Júris de policiais militares em São Paulo

3 Relatos de observação: o que vi nos Júris de policiais militares

4 Considerações finais

5 Referências Bibliográficas

\section{Resumo}

Este trabalho apresenta resultados parciais de uma pesquisa em andamento cujo objeto é o tratamento judicial dos homicídios dolosos praticados por policiais militares no sistema de justiça de São Paulo em diferentes âmbitos do Direito, seja criminal, administrativo ou cível. Foram estudados múltiplos casos. 0 estudo de caso "convida os pesquisadores em direito a observar o sistema de justiça sem as barreiras impostas pelas áreas jurídicas, a atentar às interações processuais e às suas implicações ao desfecho do caso" (Machado, 2014, p. 14). Foram, portanto, valorizadas a leitura e análise dos documentos pertinentes, bem como observações participantes nos Júris, além de entrevistas semidirigidas com os profissionais de diversas instituições da área. Assim, o "olhar" sobre o tratamento jurídico e judicial dos homicídios dolosos praticados por policiais militares nos remete ao “olhar etnográfico", sensibilizado pela teoria disponível. Um olhar atento aos rituais, encenações e estratégias dos atores no jogo que é o Tribunal do Júri. O "ouvir" demanda a "criação de espaços semânticos compartilhados por ambos os interlocutores", isto é, cabe ouvirmos como os atores que operam nas diferentes áreas reconstroem o grave problema da letalidade policial durante suas ações. O "escrever" conduz à reconstrução de narrativas que comporão o mosaico desenhado pela pesquisadora, a partir de hipóteses como a de que a atuação do Estado nos processos de responsabilização varia radicalmente conforme as características sociais e étnico-raciais das vítimas.

10 presente artigo é uma versão revisada do trabalho apresentado no V ENADIR - Encontro Nacional de Antropologia do Direito (2017). GT.9: Antropologia do Estado. Agradeço os comentários de Juliana Farias e Juliana Vinuto Lima, coordenadoras do GT, e de Maíra Machado e Riccardo Cappi, na ocasião da elaboração deste texto. 2 Mestranda pela Escola de Direito de São Paulo da Fundação Getúlio Vargas. Integrante do Grupo de Pesquisa em Criminologia da UNEB e do Núcleo de Estudos sobre o Crime e a Pena da FGV Direito SP. Bolsista FAPESP: Processo nº00239-4/2017: polianasferreira@ hotmail.com 


\section{TO LOOK, TO LISTEN AND TO WRITE DURING MILITAR POLICEMEN'S COURT TRIALS IN SÃO PAULO // Poliana da Silva Ferreira}

\section{Keywords}

military police jury / intentional homicides committed by military police officers / judgment of $\mathrm{PM}$ / death resulting from police intervention

HIIIIIIIIIIIIIIIIIIIIIIIIIIIIIIII

\begin{abstract}
This paper presents some partial findings of an ongoing research about the criminal justice treatment of deaths resulted by police approaches in the state of São Paulo. The research wants to comprehend the outcomes of those cases in different areas of the legal system, criminal, administrative and civil. Methodologically it will use multiple case studies. In the legal field, case studies "invite the legal researcher to observe the legal system without the barriers imposed by other legal areas, to pay attention to the process interactions and its implications in the case outcomes" (Machado, 2014, p. 14). In addition, participant observations of juries as well as semi-guided interviews with law professionals and analysis of the legal processes will be conducted. The ethnography "look" at the legal and judicial treatment of lethal military police approaches involves attentive observation of rituals, performances and strategies of actors or players in the game that is the jury courtroom. The ethnography "listening" indicates the need to "create semantic spaces shared by both interlocutors", which means listening to how the actors that operate in those cases reconstruct the grave problem of police lethality. At last, the "writing" directs us to the reconstruction of narratives that will integrate the mosaic designed by the researcher. This step takes into account the research hypothesis that the State dealing of those cases varies radically in accordance with social and ethnic racial characteristics of the victims in all three legal areas of this study.
\end{abstract}




\section{Introdução}

Este trabalho tem por finalidade apresentar os resultados parciais de uma pesquisa de mestrado, ainda em andamento, cujo objeto é o tratamento judicial dos homicídios dolosos praticados por policiais militares no sistema de justiça de São Paulo. A pesquisa visa compreender especificamente como diferentes âmbitos do Direito - criminal, administrativo ou civil - têm responsabilizado policiais envolvidos em abordagens cujo desfecho foi a morte de um ou mais cidadãos.

O estudo do tratamento judicial das mortes decorrentes de intervenção policial é importante, pois nos ajuda a compreender, entre outros aspectos, porque o Brasil é um dos países que apresenta um dos mais altos níveis de letalidade decorrente de ações policiais. 0 panorama numérico dessas mortes, apesar de nos dar apenas uma das dimensões do problema, permite observar um quadro nacional mais do que preocupante. Segundo o Anuário do Fórum Brasileiro de Segurança Pública (2016), 3.320 pessoas foram mortas em decorrência de intervenções policiais apenas no ano de 2015 e, entre 2009 e 2015, o acúmulo foi de 17.688 mortos por essa mesma causa no Brasil.

No estado de São Paulo, o perfil das vítimas da letalidade policial é composto por pessoas "negras (61\%), homens (97\%) e jovens, entre 15 e 29 anos de idade" (Sinhoretto et ali, 2014, p. 10), moradoras de regiões periféricas da cidade (Alves, 2011).

Para o presente texto, serão priorizadas discussões em torno do tratamento jurídico-criminal dado a casos de mortes oriundas de abordagens policiais, especialmente casos que chegam ao Tribunal do Júri. É, portanto, a cena do Júri que interessou observar e relatar a partir de certos elementos observados.

Assim, formulei as seguintes questões iniciais: quais elementos podem ser auferidos nas observações dos Júris dos policiais militares envolvidos em abordagens que resultaram morte? Como o "olhar etnográfico" pode contribuir para um novo conhecimento nesse campo? Como ouvir e olhar, de um ponto de vista metodológico? Enfim, como essas operações podem colocar em confronto considerações do senso-comum?
Para produzir respostas a essas questões, o texto está dividido em duas partes. Na primeira, há uma descrição de como a pesquisa tem se desenvolvido, com destaque para as estratégias metodológicas adotadas. Em seguida, são apresentados alguns resultados parciais.

\section{Estratégias metodológicas}

Duas estratégias metodológicas foram utilizadas: o estudo de caso e a observação participante. Antes de escolhê-las, levei em consideração a revisão de literatura especializada ${ }^{3}$, que diagnosticou existir uma carência de pesquisas empíricas no Direito dedicadas ao tratamento jurídico das abordagens policiais com resultado morte.

Assim, observando as poucas pesquisas voltadas para essa questão e buscando manter um diálogo com as que têm contribuído com o campo, ao longo dos últimos vinte anos, sobretudo as inscritas na Sociologia e na Antropologia, minha pesquisa se debruça sobre os conflitos e tensões entre o campo das normas que instituem as abordagens policiais e sancionam desvios, e o campo das práticas, aquele em que os atores operacionalizam as normas de maneira específica no cotidiano das instituições do sistema de justiça.

Antes de mais nada, vale dizer que se trabalhou com o estudo de caso. No campo do Direito, o estudo de caso "convida os pesquisadores em direito a observar o sistema de justiça sem as barreiras impostas pelas áreas jurídicas, a atentar às interaç̃oes processuais e às suas implicações ao desfecho do caso" (Machado, 2014, p. 14).

Entre as inúmeras vantagens dessa estratégia metodológica, Triviños destaca que "o grande valor do estudo de caso está em oferecer o conhecimento aprofundado de uma realidade delimitada e os resultados atingidos podem permitir formular hipóteses para

3 Etapa da pesquisa realizada entre outubro de 2016 e março de 2017, na Plataforma Google Acadêmico e no Catálogo de Teses e Dissertações da CAPES. Para as buscas, utilizou-se as palavras-chave: "auto de resistência", "homicídios dolosos praticados por policiais", "resistência seguida de morte", "julgamento de policiais", "mortes praticadas por policiais". Das pesquisas catalogadas, notou-se que a maioria se inscrevia nas áreas da Sociologia, Ciência Política e Antropologia, e as poucas, no âmbito do Direito, optavam por tratar o tema de forma estritamente teórica ou dogmática. 
o encaminhamento de outras pesquisas" (Triviños, 1987, p. 111). Nesse sentido, foram escolhidos três casos como universo de análise: o "universo sobre o qual o pesquisador trabalha, ou que ele tem ao seu alcance" (Pires, 2008, p. 166). Esses casos, por suas características e particularidades, permitiram estudar as atividades do sistema de justiça com seus diversos atores, momentos e contextos.

$\mathrm{O}$ acesso aos casos, pensado como um dos critérios de escolha (Pires, 2008), deu-se mediante diferentes canais informativos: mídia, serventuários da justiça, juízes, promotores e advogados. Ainda sobre os critérios de escolha dos casos, pode-se destacar a pertinência teórica, pois todos os escolhidos têm relação direta com os objetivos e hipóteses de trabalho da pesquisa, isto é, são casos de abordagens policiais, com resultado morte, tramitando no sistema de justiça e que alcançaram diferentes áreas e instâncias.

Escolhidos os três casos - aqui denominados caso do motoboy, caso do publicitário e caso da farsa do réveillon - passa-se à segunda estratégia metodológica, ligada ao desenvolvimento do projeto de pesquisa em si: a observação participante como técnica de coleta de dados.

\subsection{O escrever sobre a observação dos Júris de policiais militares em São Paulo}

Antes de apresentar minhas percepções a respeito do que tenho observado e de como o fiz, vale a pena destacar o que tem sido a tarefa de escrever neste trabalho. O escrever aqui, tem demandado um exercício que vai além de sintetizar o que a doutrina e a jurisprudência têm dito sobre o tema. O escrever tem conduzido à reconstrução das narrativas que comporão o mosaico construído a partir das falas, das ações e dos olhares dos atores que atuam no Tribunal do Júri, tudo isto por meio da minha própria maneira de ver o problema.

O escrever para relatar uma observação remete à ideia elaborada por Mariza Peirano (2014) sobre o que se espera da elaboração teórica em um trabalho monográfico. Assim, as atividades de escrever e de elaborar uma teoria não são um detalhe, mas um exercício metodológico realizado a partir do que se viu, ouviu e sentiu. A narração desses elementos é feita em conjunto com a produção teórica de determinado objeto de pesquisa. Nesse sentido,

não se trata de um "detalhe metodológico" que antecede uma teoria; a indagação etnográfica em si já tem um caráter teórico, porque somente (ou principalmente) ela nos permite questionar os pressupostos então vigentes pelas novas associações ou novas perguntas que nos proporciona (...) (Peirano, 2014, p. 385).

Portanto, é no próprio narrar a experiência etnográfica que se teoriza (Peirano, 2014; Schritzmeyer, 2012). Com base nesse conceito do que é escrever, e ciente que a minha imersão no campo não pode ser comparada às pesquisas de quem passou anos envolvido em determinada comunidade ou grupo como objeto de estudo, escrevo abaixo o resultado da minha experiência com os Júris de policiais militares na cidade de São Paulo.

"Olhar" a fase do Júri e ao tratamento judicial dado aos homicídios dolosos praticados por policiais militares, remete ao "olhar etnográfico", ao olhar sensibilizado pela teoria disponível (Oliveira, 1996; Cappi, 2014): um olhar atento aos rituais, encenações e estratégias dos atores no jogo que é o Tribunal do Júri (Schritzmeyer, 2012), que é construído também a partir da observação participante.

A observação participante é entendida, aqui, "como um processo pelo qual um pesquisador se coloca como observador de uma situação social, com a finalidade de realizar uma investigação científica" (Minayo, 2010, p. 54) e é utilizada especialmente porque o interesse da pesquisa reside na compreensão da natureza do fenômeno e não na avaliação da magnitude ou distribuição das abordagens policiais com resultado morte.

Vale ressaltar que, junto com o refinamento da observação, veio também o processo de estranhamento, similar à ideia apontada por Baptista (2007) e Peirano (2014) e que, segundo Olney Assis e Vitor Kümpel (2011), "significa perplexidade diante de uma cultura diferente" (Assis \& Kumpel, 2011, p. 26). É um ato que implica reconhecer que algo, considerado natural, possa ser problematizado. 
Assim, apesar de, antes da realização da pesquisa, eu já ter acompanhado inúmeros Júris, seja na condição de estagiária ou mesmo de advogada, o exercício de observá-lo como pesquisadora permitiu-me captar olhares, gestos, comportamentos e falas que outrora poderiam passar despercebidos.

A observação participante ${ }^{4}$ surgiu na pesquisa ainda nas primeiras atividades de campo, quando eu tentava escolher os casos.

\section{Relatos de observação: o que vi nos Júris de policiais}

Em dezembro do ano passado, comecei a buscar processos nos Tribunais do Júri de São Paulo cujos réus fossem policiais que haviam atuado em abordagens que resultaram morte de civis.

Tal busca me levou a frequentar, semanalmente, o Fórum Criminal da Barra Funda. Isto foi necessário já que no estado de São Paulo não há uma identificação a priori desses processos. Apenas os serventuários da justiça, advogados ou membros do Ministério Público que atuam ou atuaram em processos desse tipo conseguem informar quais são os processos oriundos de mortes decorrentes de intervenção policial, a partir da pauta mensal de determinado Tribunal do Júri.

A frequência ao Fórum Criminal da Barra Funda na busca de casos a serem estudados garantiu um aporte importante em relação à minha entrada em campo: a construção de um filtro para aquilo que eu estava observando. Assim, passei a observar os Júris - até agora foram seis - cujos réus eram policiais militares e selecionei três casos.

O ambiente forense, enquanto palco de atuação dos diferentes atores que me propus a observar, guarda algumas particularidades. Trata-se de um local onde os rituais de diferenciação social são explicitados formal e informalmente. Do ponto de vista formal, é

4 Vale salientar que esse exercício, apesar de conferir uma inspiração etnográfica à pesquisa, de maneira alguma a torna uma pesquisa antropológica ou etnográfica. A pesquisa continuou inscrita no Direito, mas a própria complexidade do problema de pesquisa demandou o uso de técnicas tradicionalmente mais vinculadas às áreas da Antropologia e da Sociologia. possível observar, por exemplo, que há acessos físicos diferenciados no prédio: entrada de pedestres ou de veículos autorizados para magistrados, membros do Ministério Público, serventuários da justiça; entrada para advogados, serventuários, estagiários (desde que se identifiquem como tais) e entradas para o público em geral, todas sinalizadas e fiscalizadas. Regras explícitas também autorizam ou restringem determinadas pessoas em áreas internas do Fórum, assim como diferenciam os horários de acesso ao prédio.

Do ponto de vista informal, é possível observar que essas regras de acesso são flexibilizadas a depender, substancialmente, de dois elementos: do funcionário que fiscaliza e da aparência de quem acessa o Fórum. Por diversas vezes presenciei pessoas que não se identificaram como advogados, serventuários ou estagiários passarem pelo acesso restrito. Eu mesma vivenciei a experiência de estar com um advogado um homem branco de meia-idade, vestido de terno e gravata - que sem sua carteira de identificação teve o acesso permitido, enquanto eu fui obrigada a me identificar como advogada para entrar pelo mesmo acesso- mulher negra, de tranças, jovem, que na ocasião usava um vestido e paletó pretos. Em outra ocasião, porém, acessei a mesma entrada sem qualquer identificação.

Outras regras, como o uso do refeitório exclusivo para funcionários, o acesso ao plenário antes do sorteio dos jurados por quem não foi convocado, o uso de celulares e de câmeras filmadoras também são flexibilizados.

Ainda no contexto da diferenciação informal, outro elemento me chamou a atenção. Um olhar atento sobre os transeuntes que formavam duas filas principais de acesso ao prédio me fez perceber uma distinção sócio-racial: de um lado, a fila menor, era composta majoritariamente por pessoas brancas e do sexo masculino, de terno e gravata, sapato e outros itens de vestuários sociais. Ostentam relógios de pulso, celulares de marca seletas, pastas de couro. Do outro lado, numa fila que chegava a ter mais que o triplo da anterior, pessoas se amontoam para entrar no Fórum, a maioria negra, de ambos os sexos, vestidas de forma humilde, muitas calçando chinelos e com seus documentos em sacolas plásticas. 
Quanto à estrutura física, as salas em que assisti aos Júris também me pareceram conter marcas diferenciadoras. Os Júris que tiveram suas datas divulgadas anteriormente em veículos de comunicação de massa aconteceram no plenário dez, uma espécie de auditório com mais de duzentos e cinquenta lugares. $\mathrm{E}$ os demais, sem grande repercussão midiática, aconteceram nos plenários treze e catorze, salas menores, com cerca de cinquenta lugares.

No que diz respeito aos Júris em si, o primeiro que assisti, notei que havia uma intensa movimentação interna dos serventuários da justiça para acompanhar o caso e uma espécie de euforia que rondava os corredores. Os funcionários falavam animadamente, entre si, sobre suas expectativas a respeito do desfecho do julgamento, antes mesmo do início da sessão. Trocavam mensagens e se revezavam no plenário, para não perder os lugares conquistados na sala que já estava cheia, com pessoas amontoadas do lado de fora da sala de julgamento para acompanhar aquela sessão. Tratava-se do julgamento de policiais militares, réus em um processo que teve ampla divulgação nos meios de comunicação à época dos fatos.

O que parecia atrair tanta gente àquele plenário, interessada em acompanhar o julgamento daqueles réus, não eram propriamente os réus, mas a vítima. A mobilização que lotou um dos maiores plenários do Fórum Criminal deveu-se ao fato de que "a vítima estava fora dos padrões comuns ${ }^{5}$ ", ou melhor, contrariava parte das estatísticas relativas ao perfil das vítimas de letalidade policial. Tratava-se de um homem de 35 anos de idade, branco, publicitário, morador de um bairro privilegiado da cidade de São Paulo.

O movimento de euforia era realizado não só pelos serventuários com os quais conversamos, mas por profissionais da imprensa convocados para cobrir o caso, policiais militares, amigos e familiares dos réus.

Nesse primeiro Júri houve lotação contínua do plenário diante do esvaziamento que caracterizou os

5 Fala de jornalista registrada em sessão etnografada no dia 25 de outubro de 2016, das 10 h30 às 21h40, no Plenário 10 do V Tribunal do Juri, Foro Central Criminal, Fórum Min. Mário Guimarães, São Paulo- SP. demais julgamentos. Nesses, as sessões iniciavam-se cheias de curiosos e de jurados ainda não sorteados e, passado o sorteio, esvaziavam-se quase por completo e permaneciam assim até a réplica do Ministério Público, quando então o espaço passava a ser tomado por policiais militares que, de plantão na ocasião, dirigiam-se às salas onde, não por coincidência, um de seus colegas estava sendo julgado.

Sérios, de braços cruzados, a maioria sem uniforme, de pé, possivelmente na expectativa de falas fortes do Ministério Público, os policiais militares chegavam em pequenos grupos. Tal presença maciça nesse momento tinha certamente uma ou mais significações. Tratava-se de dar apoio ao companheiro de corporação, de intimidar os jurados ou o próprio membro do Ministério Público. Este, inclusive, podia, por sua vez, explorar a presença da multidão de policiais em seu favor. Em uma audiência, o Promotor bradou: "todos vocês aí atrás, de braços cruzados, com cara feia, é o quê?! Para me intimidar?! Imagino que não, porque vocês sabem que o Ministério Público é parceiro da Polícia Militar. Cara feia pra mim é fome ou dor de barriga”.

A parceria mencionada por esse promotor específico, naquela sessão de julgamento, remeteu a uma fala desse mesmo promotor, fora do ambiente forense, quando ele proferiu um discurso em redes sociais, no qual disse, diante de uma passeata que impedia a passagem de seu carro: "por favor, alguém poderia avisar a Tropa de Choque que essa região faz parte do meu Tribunal do Júri e que se eles matarem esses filhos da puta eu arquivarei o inquérito policial (... $)^{7}$ ". Apesar da fala ter sido dita fora do ambiente forense, ela integra o campo, a medida que aquele promotor não deixa de ser promotor quando sai do Fórum. Suas ações, ainda que no âmbito privado, repercutem sobre sua atuação no Júri.

Emblemática, não só por incitar o que tem sido uma das mais graves e persistentes violações de direitos

6 Sessão do Júri etnografada no dia 26 de outubro de 2016, das 10 h30 às 23h00, no Plenário 10 do V Tribunal do Júri, Fórum Min. Mário Guimarães, São Paulo - SP.

7 Para saber mais, ver ROVER, T. MP vai investigar promotor sobre incitação à violência. Consultor Jurídico ConJur. 10 de junho de 2013. Disponível em http://www.conjur.com.br/2013-jun-10/mp-sp-investigar-promotor-incitou-violencia-manifestantes 
humanos - a letalidade policial -, mas também, e especialmente, por vir de um ator que, em tese, trabalha diariamente no enfrentamento daquelas ações, tal fala do promotor repercutiu na esfera administrativa, de modo que ele respondeu a um processo administrativo perante o Conselho Nacional do Ministério Público e sua previsível, ou melhor, possível responsabilização foi utilizada em seu próprio repertório em dois dos seis Júris que acompanhei.

Um olhar atento tem me levado a observar outros elementos, para além da atuação pontual dos atores que operam nessa seara. Assim, noto que em todos os casos observados, os jurados, destinatários últimos de todo o ritual e procedimentos realizados no Júri, paradoxalmente pouco participam das sessões. São chamados no início do julgamento para julgarem a causa, a partir de suas convicções, e para prestarem atenção nas narrativas que ali serão colocadas, mas poucas são as tentativas de participação efetiva dos jurados ao longo dos julgamentos. Nenhum fez perguntas à acusação ou à defesa durante as intervenções, tampouco os jurados requisitaram os autos do processo para verificar quaisquer provas ali acostadas.

O que se nota é que as pessoas sorteadas parecem pouco envolvidas com o que se passa diante delas. Muitas passam boa parte do tempo olhando para o plenário, para o relógio, ou com um olhar perdido sobre o cenário em que se encontram, como que incrédulas frente à missão que acabaram de receber. Dos jovens aos mais velhos, a postura nas cadeiras ou o andar entre a sala de julgamento e o sanitário, durante os intervalos, acaba denunciando não só a falta de envolvimento com o caso - traindo, talvez, até um certo desprezo - como também a exaustão que parece mais evidentemente nas últimas horas de julgamento. Em alguns casos, ela é demonstrada desde as primeiras horas, através de respirações profundas, bocejos, pedidos de intervalos para um café, ou pedem que não haja intervalos para que o julgamento não se prolongue.

Os réus, por sua vez, em nada demonstram impaciência. Têm postura ereta, sentados com os pés alinhados, cabeça levemente inclinada. Quase a pedir perdão, aguardam e observam cada ato da acusação e da defesa praticamente imóveis. E assim se colocam durante todo o julgamento.
Em todos os casos que foram assistidos, os réus foram interrogados e escolheram abrir mão do direito ao silêncio. Falaram, choraram, narravam suas versões de forma clara e segura: indicaram o local e as condições em que o fato aconteceu, suas preocupações, a rapidez das ações, a injusta agressão que acreditavam ter sofrido - ou estavam na iminência de sofrer -, a legítima defesa, as tensões, suas condições de trabalho, o histórico na corporação, as medalhas recebidas.

Quanto às testemunhas, figuraram como vinculadas à defesa do réu, em regra, policiais ex-colegas de batalhão, que relataram o histórico de bom comportamento. Também compareceram familiares de réus que se dedicavam a descrever em plenário o sofrimento do parente acusado ao passar por aquela experiência ou o seu próprio sofrimento ao ver o réu ser preso e processado por "defender a sociedade", expressão recorrente nas falas dos familiares de réus que testemunharam me juízo. As testemunhas de acusação foram mais restritas, na maioria dos Júris assistidos. Eram autoridades que haviam registrado o fato na delegacia, peritos que produziram laudos constantes dos autos e outros policiais que participaram da mesma ação, mas que não foram denunciados pelo membro do Ministério Público.

Acusação e defesa se revezaram em plenário com diferentes recursos. A primeira, na figura de um dos membros do Ministério Público, normalmente acusou formalmente os réus, baseando-se nos termos da sentença de pronúncia e apoiando-se, além de em relatos de testemunhas de acusação, especialmente em laudos de exame de balística e de exame cadavérico. Em pelo menos cinco dos seis Júris assistidos o membro do Ministério Público se baseou na hipótese de o acusado ter realizado uma execução sumária da vítima.

As defesas, exercidas em todos os Júris por advogados particulares (pagos pelos acusados), centraram suas narrativas nos históricos dos policiais na corporação e em quem haviam sido as vítimas, buscando desqualificá-las enquanto tais. Em todos os casos, a tese sustentada por defensores foi a de legítima defesa. 


\section{Considerações finais}

Neste trabalho propus apresentar os resultados parciais de uma pesquisa de mestrado, cuja preocupação é o tratamento dado no sistema de justiça a abordagens policiais com resultado morte. $\mathrm{O}$ objetivo foi compartilhar alguns achados e preocupações que surgiram ao longo das observações dos Júris realizados na pesquisa.

Em um primeiro momento, apresentei as estratégias metodológicas utilizadas e as razões de certas escoIhas. Em seguida, em breves notas, expus o que tem sido a tarefa de escrever sobre os Júris de policiais militares que se envolveram em abordagens policiais com resultado morte, assim como, alguns resultados da observação.

Do ponto de vista metodológico, ficou claro que a complexidade do problema - como o sistema de justiça trata as abordagens policiais com resultado morte - $\mathrm{Ca}$ rece de um tratamento interdisciplinar, em que diferentes áreas e, portanto, métodos, se apropriem do tema.

Por isso, o olhar, o ouvir e o escrever são tarefas que precisam estar intrinsecamente concatenadas em um exercício complementar. Os Júris de policiais militares decorrentes de abordagens policiais que resultaram em morte nos demandam o difícil exercício de assumirmos que fazer pesquisa é estar fora da própria zona de conforto.

111111111111111111111111111111111111

\section{Referências}

Assis, O. Q. \& Kümpel, V. F. (2011). Manual de antropologia jurídica. São Paulo: Saraiva.

Alves, J. A. (2011). Topografias da violência: necropoder e governamentalidade espacial em São Paulo. Revista do Departamento de Geografia - USP, Volume 22, pp. 108-134.

Cappi, R. (2013). "Maneiras de pensar" o controle social e a justiça penal: uma análise dos discursos parlamentares sobre a redução da maioridade penal. Revista de Estudos Empíricos em Direito, vol. 1, n. 1, jan 2014, pp. 10-27.

Dewalt, K. \& Dewalt, B. (2011). Participant Observation: A Guide For Fieldworkers. United Kingdom: Altamira Press.

Figueira, L. E. V. (2007). O Ritual Judiciário do Tribunal do Júri: O caso do ônibus 174. Tese (Doutorado), Universidade Federal Fluminense, Niterói, 238f.

Flauzina, A.L.P. (2006). Corpo Negro Caído No Chão: sistema penal e o projeto genocida do Estado brasileiro. Dissertação (Mestrado) - Pós-Graduação em Direito, Universidade de Brasília, Brasília.

Machado, M. R. \& Ferreira, L. M. (org.). (2014). Estudos sobre o caso TRT. São Paulo: Direito GV, p. 380.

Minayo, M. C. S. (org.). (2010). Pesquisa social: teoria, método e criatividade. 29. Ed. Petrópolis, RJ: Vozes.

Misse, M., Grillo, C., Teixeira, C. P. \& Neri, N. (2013). Quando a polícia mata: homicídios por "autos de resistência" no rio de janeiro (2001-2011). Rio de janeiro: CNPQ/NECVU/BOOKLINK.

Oliveira, R. C. (1998). O trabalho do antropólogo: olhar, ouvir, escrever. In: O trabalho do antropólogo. São Paulo: Ed. da UNESP, pp. 1735.

Peirano, M. (2014). Etnografia não é método. Horizontes antropológicos, Porto Alegre, ano 20, n. 42.

Pinheiro, P. S. (1997). Violência, crime e sistemas policiais em países de novas democracias. Tempo social: revista de sociologia da USP, São Paulo, maio, vol. 9, n. 1, pp. 43-52.

Reis, V. (2005). Atucaiados pelo Estado: as políticas de segurança pública implementadas nos bairros populares de salvador e suas representações, 19912001. 247f. Dissertação (Mestrado em Ciências Sociais), Universidade Federal da Bahia, Faculdade de Filosofia e Ciências Humanas. 
Schritzmeyer, A. L. P. (2012). Jogo, ritual e teatro: um estudo antropológico do Tribunal do Júri. São Paulo: Terceiro Nome.

Sinhoretto, J., Silvestre, G. \& Schlittler, M. C. (2014). Desigualdade racial e segurança pública em São Paulo: letalidade policial e prisões em flagrante. São Carlos: Universidade Federal de São Carlos.

Souza, T. L. S. (2010). Constituição, Segurança Pública E Estado De Exceção Permanente: a biopolítica dos autos de resistência. 222f. Dissertação (Mestrado em Direito), Pontifícia Universidade Católica do Rio de Janeiro, Departamento de Direito, 2010.

Strauss, A. \& Corbin, J. (2008). Pesquisa Qualitativa: Técnica E Procedimentos Para O Desenvolvimento Da Teoria Fundamentada. $2^{\mathrm{a}}$ Edição. Porto Alegre: Artmed.

Triviños, A. N. S. (1987). Introdução à Pesquisa em Ciências Sociais: A Pesquisa Qualitativa Em Educação. São Paulo: Editora Atlas S. A.

Zaccone D'elia filho, O. (2015). Indignos de vida: a forma jurídica da política de extermínio de inimigos na cidade do Rio de Janeiro. Rio de Janeiro, Revan.

Yin, R. (2001). Estudo de Caso: Planejamento E Métodos. Tradução Daniel Grassi. 2 Ed. Porto Alegre: Bookman. 